\title{
O USO DE ESTUDOS DE CASO EM PESQUISAS SOBRE POLÍTICA AMBIENTAL: VANTAGENS E LIMITAÇÕES
}

\author{
Andrea Steiner
}

\section{RESUMO}

A análise das questões ambientais em um contexto político é um tema de estudo crescente na Ciência Política, mas que requer considerações metodológicas específicas. Um dos métodos utilizados com mais freqüencia nas pesquisas ligadas à política ambiental é o estudo de caso. O objetivo deste artigo é discutir o papel dessa metodologia nessa subdisciplina. Delineia-se questões conceituais gerais sobre o método, suas vantagens e desvantagens; distingue-se o estudo da política ambiental de outros temas de pesquisa dentro da Ciência Política, contextualizando suas necessidades metodológicas específicas; e analisa-se o papel dos estudos de caso nas pesquisas sobre politica ambiental, abordando suas ambigüidades inerentes e as vantagens e limitações gerais da metodologia e de cinco formas de análise e extração de inferências. análise de covariância, uso de contrafatuais, process tracing causal, teste de congruência e comparação entre casos. Dentre essas cinco abordagens, duas destacam-se para as pesquisas político-ambientais, apesar de ocuparem posições quase que opostas em termos de vantagens práticas e aplicabilidade: process tracing causal e uso de contrafatuais. O uso complementar dessas e outras abordagens, seja em um ou mais estudos sobre temas de política ambiental, é extremamente útil para o desenvolvimento empírico e teórico dessa subdisciplina.

PALAVRAS-CHAVE: estudos de caso; politica ambiental; metodologia em Ciência Política; metodologia qualitativa.

\section{INTRODUÇÃO}

A análise das questões ambientais em um contexto político é um tema que vem sendo cada vez mais estudado dentro da Ciência Política. Entretanto, isso nem sempre é tarefa fácil, dada a complexidade social do sistema político somada à complexidade ecológica dos sistemas naturais, que englobam a sociedade de maneira aninhada $\mathrm{e}$ interconectada. Por isso, o estudo da interface política-meio ambiente requer considerações metodológicas específicas, conforme já apontado por vários autores, como Homer-Dixon (1996), Mitchell e Bernauer $(1998 ; 2004)$ e Zürn (1998).

O estudo de caso é uma metodologia usada com bastante freqüência nas pesquisas ligadas à política ambiental. De fato, é um método comum de investigação dentro da Ciência Política de modo geral, e como qualquer metodologia cien- tífica, possui vantagens e limitações com maior ou menor importância de acordo com cada tipo de estudo. Em uma reedição do seu livro clássico sobre estudos de caso, Yin (2009) sugere que o sucesso do método dependerá do tipo de indagação da pesquisa, do nível de controle sobre os eventos pesquisados e da época que está sendo enfocada (contemporânea ou histórica). Essa constatação possui relevância especial em temas ligados à interface meio ambiente-política, principalmente em relação ao nível de controle do evento em questão (comumente baixo no que diz respeito aos problemas ambientais) e à época em foco (muitos dos problemas ambientais são recentes). Em ambos os pontos, conforme veremos com maior detalhe ao longo do texto, o posicionamento de muitas das temáticas político-ambientais apresentam-se como problemas de pesquisa ideais para o uso da metodologia de estudo de caso. 
O objetivo deste artigo é discutir o papel da metodologia de estudo de caso em pesquisas na área de política ambiental, mostrando as vantagens e limitações relevantes para essa subdisciplina. Para tanto, inicia-se com uma discussão conceitual sobre o método, listando suas forças, fraquezas gerais e algumas das principais abordagens utilizadas. A seguir, distingue-se o estudo da política ambiental de outros temas de pesquisa dentro da Ciência Política, contextualizando suas necessidades metodológicas específicas. O próximo tópico une as duas discussões e analisa o papel dos estudos de caso nas pesquisas sobre política ambiental, abordando suas ambigüidades inerentes e as vantagens e limitações gerais da metodologia e de algumas das formas de análise possíveis. Encerra-se com algumas considerações gerais sobre o tema.

\section{PARA QUE SERVE UM ESTUDO DE CASO?}

Para entender o papel dos estudos de caso nas pesquisas sobre política ambiental, é preciso, primeiramente, ter uma compreensão conceitual mais aprofundada sobre essa metodologia, para que serve e em quais circunstâncias não se aplica. Afinal, apesar de amplamente utilizada dentro das Ciências Sociais, a metodologia de estudo de caso é pouco compreendida, vista com preconceito e até taxada de pouco científica (GERRING, 2004, p. 341; YIN, 2009, p. 15). De fato, o método tem várias desvantagens e limitações inerentes (agravadas pelo freqüente mau uso), como veremos a seguir; porém, vários autores identificam uma série de vantagens (ver, por exemplo, KING, KEOHANE e VERBA, 1994; BENNETT, 2004; GERRING, 2004; BENNETT e ELMAN, 2006).

Existem diversas definições sobre o que seria um estudo de caso. Para Yin (2009), o estudo de caso seria o método mais apropriado para perguntas do tipo "como?" e "por quê?", com temas sobre os quais o pesquisador tem pouco controle e com enfoque em algum fenômeno contemporâneo. Assim, traz o seguinte conceito: "Um estudo de caso é uma investigação empírica que pesquisa um fenômeno contemporâneo dentro do seu contexto real, principalmente quando os limites do fenômeno e do seu contexto não estão claramente evidentes [...]. A pergunta do estudo de caso lida com uma situação tecnicamente distinta, na qual haverá mais variáveis de interesse que pontos de dados e que, conseqüentemente, conta com fontes múltiplas de evidências e dados que precisam convergir de maneira triangular, além de se beneficiar do desenvolvimento prévio de proposições teóricas para guiar a coleta e análise dos dados" (idem, p. 13-14).

Há também definições mais restritivas como a de Bennett, que define a metodologia de estudo de caso como "análises de casos únicos e comparações entre um pequeno número de casos" (BENNETT, 2004, p. 21), ou mais amplas, como a de Van Wynsberghe e Khan, "[...] heurística transparadigmática e transdisciplinária, que envolve a delineação cuidadosa dos fenômenos para os quais a evidência está sendo coletada" (VAN WYNSBERGHE \& KHAN, 2007, p. 80). Porém, para os propósitos deste artigo, utilizaremos a definição sugerida por Gerring, em uma revisão conceitual do método que o descreve como: "[...] um estudo intensivo de uma única unidade, com o objetivo de generalizar para um grupo maior de unidades. Os estudos de caso contam com o mesmo tipo de evidência de covariância usado em outros tipos de pesquisa. Assim, o método de estudo de caso pode ser compreendido corretamente como um modo específico de definir casos, não uma forma de analisar casos ou uma maneira de modelar relações causais" (GERRING, 2004, p. 341).

Nesse contexto, Gerring traz as seguintes delineações: uma "unidade" refere-se a qualquer fenômeno limitado no espaço, cujo estudo enfoca um determinado momento pontual ou período histórico prolongado; cada ponto observado dentro da unidade constitui um "caso"; um grupo de unidades constitui uma "amostra"; uma amostra somada aos casos não estudados constitui uma "população". Porém, o que cada um desses termos representa na prática irá depender do desenho específico de cada trabalho, por exemplo, o grupo de eleitores de um determinado país poderá ser uma unidade ou um caso, de acordo com a pesquisa (idem, p. 351).

Ainda segundo Gerring (idem), existem três tipos básicos de estudo de caso, classificados segundo sua (co)variância espacial e/ou temporal: o tipo 1, em que a covariância pode ser observada em uma única unidade, diacronicamente (ou seja, há tanto variação espacial quanto temporal); o tipo 2, em que a covariância pode ser observada em uma única unidade, sincronicamente (inclui ape- 
nas variação espacial); o tipo 3, em que a covariância pode ser observada dentro de uma única unidade, diacronicamente (novamente com variação espacial e temporal). Também afirma que os estudos de caso podem empregar diversas abordagens, não necessariamente qualitativas ou presas a um $N$ pequeno. Nesse sentido, Bennett (2004) lista process tracing, testes de congruência, análises de contrafatuais e diversos tipos de métodos comparativos entre algumas das principais formas de análise dos estudos de caso. Similarmente, Blatter e Blume (2007; 2008b) delineiam três abordagens distintas como "tipologias ideais" de estudos de caso: estudos de caso covariantes, process tracing causal e análises de congruência. Aqui estas abordagens serão tratadas como formas de análise e extração de inferências dentro da metodologia mais ampla de estudo de caso, conforme delineado adiante.

Sete traços principais distinguem os estudos de caso de outras metodologias, de acordo com Gerring (2004). O primeiro (e mais óbvio) seria sua afinidade com estudos de maior profundidade e menor amplitude. Segundo, os casos estudados são geralmente passíveis de comparação entre si por terem origem na mesma unidade, apesar de deixarem a desejar em termos de representatividade. $\mathrm{O}$ terceiro traço aponta para sua maior ligação com a inferência descritiva e menor com a causal. Porém, dentre as investigações causais, têm como quarto traço característico promover a análise de mecanismos causais com maior segurança que a dos efeitos causais (cuja natureza é mais probabilística). Similarmente, o quinto traço mostra que o estudo de caso é uma metodologia que explica melhor relações causais sem variabilidade do que aquelas com relações de probabilidade. Em sexto lugar estaria a utilidade dos estudos de caso quando uma variância relevante só está disponível para uma única unidade (ou um pequeno número de unidades). Por fim, os estudos de caso são extremamente importantes para pesquisas pioneiras e exploratórias.

As características listadas acima podem ser vistas como vantagens em relação a outras metodologias, nos aspectos mencionados. Porém há ainda mais vantagens, como a identificação de variáveis e hipóteses novas ou omitidas, o desenvolvimento de explicações históricas sobre certos casos, altos níveis de validade teórica e a possibilidade de usar generalizações para construir modelos mais complexos de causa de efeito (BENNETT, 2004, p. 19). Da mesma forma, os diferenciais e vantagens mencionados servem para mostrar algumas das limitações dos estudos de caso, entre os quais: dificuldade de escolher casos relevantes, baixas representatividade e possibilidade de generalização, pouca capacidade de avaliar o "peso causal" das variáveis, alto nível de indeterminação e uma freqüente falta de independência entre os casos estudados (idem). Ademais, Gerring (2004) sustenta que sua aplicação para o teste e/ou confirmação de teorias é limitada.

Porém, essas desvantagens e limitações têm sua gravidade diminuída quando vemos que, de maneira geral, os estudos de caso complementam outros tipos de pesquisa e têm seu lugar garantido dentro dos inúmeros métodos utilizados nas Ciências Sociais e nos estudos sobre política ambiental.

\section{II.1. Métodos de análise}

Conforme citado anteriormente, existem diversos tipos de métodos de análise que podem ser usados nos estudos de caso. Aqui descreveremos cinco tipos importantes, com relevância especial para as pesquisas sobre política ambiental, em que permitem extrair inferências de maneira distinta: análises de covariância, uso de contrafatuais, process tracing causal, testes de congruência e comparação entre casos. O Quadro 1 traz uma síntese desses métodos. 


\begin{tabular}{|c|c|c|c|}
\hline Tipo de abordagem & Pré-condições & Observações concretas & Conclusões abstratas \\
\hline Análises de covariância & $\begin{array}{l}\text { Controle sobre outras } \\
\text { variáveis e uma hipótese } \\
\text { com base teórica para } \\
\text { verificar a direção do } \\
\text { processo causal. }\end{array}$ & $\begin{array}{c}\text { A covariância é observada } \\
\text { ao longo de um período de } \\
\text { tempo elou espaço entre } \\
\text { indicadores das variáveis } \\
\text { dependente }(Y) \text { e } \\
\text { independente }(X) \text {. }\end{array}$ & $\begin{array}{c}X \text { tem um efeito causal } \\
\text { sobre } Y \text {. }\end{array}$ \\
\hline Process tracing causal & $\begin{array}{c}\text { Observações } \\
\text { conclusivas; } \\
\text { disponibilidade de uma } \\
\text { cadeia ininterrupta de } \\
\text { evidências que fornece } \\
\text { uma visão completa e } \\
\text { detalhada dos eventos } \\
\text { dentro dos seus } \\
\text { respectivos contextos }\end{array}$ & $\begin{array}{c}\text { Mudanças temporais de } \\
\text { ações, eventos, motivações } \\
\text { e mecanismos, evidências } \\
\text { de interações entre fatores } \\
\text { causais, informações sobre } \\
\text { contextos específicos e seus } \\
\text { catalizadores ourestritivos e } \\
\text { detalhes de certos } \\
\text { resultados. }\end{array}$ & $\begin{array}{l}\text { Funcionamento real de } \\
\text { um mecanismo causal; } \\
\text { interações reais entre } \\
\text { os elementos da } \\
\text { configuração causal. }\end{array}$ \\
\hline Testes de congruência & $\begin{array}{l}\text { Pluralidade de teorias } \\
\text { correntes e coerentes de } \\
\text { onde é possível retirar } \\
\text { expectativas concretas; } \\
\text { diversidade e pluralidade } \\
\text { entre as observações } \\
\text { disponíveis. }\end{array}$ & $\begin{array}{l}\text { Correspondências e/ou } \\
\text { disparidades entre os } \\
\text { resultados empíricos e as } \\
\text { expectativas derivadas da } \\
\text { teoria utilizada. }\end{array}$ & $\begin{array}{l}\text { Relevância ou força } \\
\text { relativa de teoria(s) } \\
\text { para } \\
\text { explicar/compreender o } \\
\text { caso. }\end{array}$ \\
\hline Uso de contrafatuais & $\begin{array}{l}\text { Suficientes dados } \\
\text { empíricos e teorias } \\
\text { robustas para corstruir } \\
\text { uma situação fictícia } \\
\text { bem embasada. }\end{array}$ & $\begin{array}{l}\text { Conformidade ou } \\
\text { desconformidade com a } \\
\text { situação projetada. }\end{array}$ & $\begin{array}{c}\text { Se a situação nãoX } \\
\text { tivesse ocorrido, } \\
\text { conseqüentemente } \\
\text { não-Y teria ocorrido }\end{array}$ \\
\hline $\begin{array}{l}\text { Comparação entre } \\
\text { casos }\end{array}$ & $\begin{array}{l}\text { Existência de casos } \\
\text { comparáveis entre si. }\end{array}$ & $\begin{array}{c}\text { Semelhanças e diferenças } \\
\text { entre os casos; } \\
\text { antecedentes causais } \\
\text { comuns. }\end{array}$ & $\begin{array}{c}\text { Inferências causais } \\
\text { baseadas em causas } \\
\text { antecedentes aos } \\
\text { casos sendo } \\
\text { comparados; } \\
\text { desenvolvimento de } \\
\text { "teorias tipológicas". }\end{array}$ \\
\hline
\end{tabular}

FONTE: A autora, a partir de Fearon (1991), Bennett (2004) e Blatter e Blume (2007; 2008a; 2008b).

Segundo Blatter e Blume (2007; 2008a; 2008b), a abordagem covariante enfoca os efeitos causais. As inferências causais do estudo, por sua vez, terão origem nos indicadores observáveis desses efeitos causais ${ }^{1}$, bem como nos fatores causais. Esse tipo de abordagem procura aproximar-se ao máximo de um experimento controlado, e a evidência utilizada pode ser de origem sincrônica, diacrônica, comparativa ou histórica (GERRING, 2004, p. 343). Ademais, a relação de covariância entre as variáveis deverá fornecer algum tipo de ligação en-

\footnotetext{
${ }^{1}$ Sobre as diferenças epistemológicas dos efeitos das causas versus as causas dos efeitos ver a discussão de Bennett e Elman (2006).
}

tre as observações empíricas e uma ou mais vertentes teóricas, geralmente na forma de uma hipótese. Entretanto, não é necessário realizar observações empíricas de todo o processo causal, visto que é possível extrair conclusões abstratas baseadas na teoria que está sendo utilizada (BLATTER \& BLUME, 2007; 2008a; 2008b).

O uso de process tracing (um "rastreamento" de processos causais) é outra abordagem interessante para os estudos de caso. Conforme indicado por Mitchell e Bernauer (1998), permite a realização de pesquisas qualitativas de boa qualidade nas Ciências Sociais. É definido por George e Bennett como um método que objetiva identificar o processo causal entre uma ou mais variáveis independentes, bem como o resultado da variável 
dependente (George e Bennett apud TANSEY, 2007, p. 766). Nesse contexto, os mecanismos causais seriam processos físicos, sociais ou psicológicos impossíveis de observar-se, mas pelos quais os agentes causais agem em contextos específicos. Falleti (2006) também descreve o método de theory-guided process-tracing - uma abordagem que vai um pouco além do método original, sugerindo que a pesquisa deve fornecer narrativas teoricamente explícitas que tracem e comparem as seqüências de eventos do processo.

Os testes de congruência, por sua vez, enfocam os valores das variáveis dependente e independente, sendo possível testar se os valores esperados da variável dependente condizem com o resultado do caso em estudo. Ou seja, as inferências advêm da congruência (ou não) entre as observações realizadas e as predições que $o$ pesquisador construiu a partir das teorias disponíveis. Diferentemente da abordagem covariante, as predições não se limitam à covariância entre as variáveis independente e dependente, podendo ser bastante diversificadas (BLATTER \& BLUME, 2007, p. $8 ; 2008$ b, p. 325).

Contrariamente, o uso de contrafatuais constitui-se em analisar situações que não ocorreram na realidade: projetar cenários hipotéticos sobre como as coisas seriam caso a situação enfocada pelo pesquisador não tivesse ocorrido (um contrafatual que permite análises em termos de melhoria relativa) ou "soluções perfeitas" onde tudo o que é possível foi atingido (ou seja, até que ponto o problema foi realmente resolvido?) (FEARON, 1991). Por exemplo, no primeiro caso poder-se-ia perguntar como estariam os solos e os ecossistemas de Burkina Faso caso a desertificação jamais tivesse afetado aquele país, enquanto que no segundo indagar-se-ia como estaria a situação se o problema da desertificação tivesse sido solucionado da melhor forma possível. Outro modo de aplicar um contrafatual é fazer um exercício sobre o que ocorreria se certa variável tivesse um valor específico (BENNETT, 2004, p. 27): aproveitando o mesmo exemplo, que implicações passíveis de serem observadas e/ou testadas estariam disponíveis caso a Convenção de Combate à Desertificação tivesse sido implementada de maneira completamente eficaz em Burkina Faso? Porém, vale salientar a importância de criar contrafatuais que estejam de acordo com as teorias existentes, bem como com os resultados de outros estudos que tenham sido realizados na área estudada; contrafatuais sem bases sólidas raramente terão valor acadêmico.

O ideal seria utilizar as diferentes formas de contrafatuais de maneira complementar, contanto que os valores possíveis derivados de cada uma não fossem usados equivalentemente (UNDERDAL, 1992, p. 231). Fearon (1991) argumenta que a aplicação de contrafatuais têm um papel importante dentro da Ciência Política por ajudar na delineação de hipóteses causais, principalmente em estudos de $N$ pequeno. Entretanto, o uso de contrafatuais não se limita a estudos qualitativos. Outros autores têm desenvolvido coeficientes numéricos para estudar temas como a eficácia dos regimes, restringidos por limites superiores e inferiores; ou seja, o ótimo coletivo e o contrafatual do “não-regime”, respectivamente (SPRINZ \& HELM, 1999; HELM \& SPRINZ, 2000; SPRINZ, 2005).

Por fim, as comparações entre casos (única das cinco abordagens que requer, obrigatoriamente, a análise de mais de um caso dentro de uma unidade) são uma forma eficiente de extrair inferências causais, contanto que haja cautela para evitar erros inferenciais, comum nessa forma de análise. Bennett (2004, p. 32) destaca duas maneiras de comparar casos. Na primeira, o método de concordância direta de John Stuart Mill, é necessário buscar antecedentes causais comuns aos casos estudados e que sejam, de modo ideal, condições necessárias a eles. Na segunda maneira, o método de comparação enfocada e estruturada de casos, desenvolvido por Alexander George, o pesquisador deve "[...] definir o objetivo de pesquisa, inclusive a classe de eventos a ser explanada, a hipótese alternativa sob consideração e a forma como irá ocorrer a construção de teorias. Segundo, o pesquisador deve especificar as variáveis independentes, dependentes e intervenientes e decidir quais deverão ser controladas e quais devem variar entre os casos ou tipos de casos. Terceiro, o pesquisador seleciona os casos a serem estudados, possivelmente assistido pelo espaço tipológico que resulta da especificação das variáveis e variáveis alternativas. Quarto, o pesquisador deve considerar como melhor descrever a variância nas variáveis independentes e dependentes, considerando não apenas as variáveis individuais, mas também os tipos de casos ou combinações de variáveis, e os caminhos seqüenciais que caracterizam cada tipo. Finalmente, o pesquisador especifica as perguntas estruturadas a serem feitas para 
cada caso para estabelecer os valores das variáveis independentes, intervenientes e dependentes" ${ }^{2}$ (idem, p. 26).

Nesse sentido, aponta para a utilidade dos estudos de caso na criação de teorias tipológicas, que seriam generalizações sobre os diferentes padrões causais possíveis de ocorrer para o fenômeno enfocado. De modo geral, o autor advoga o uso complementar dessas duas formas de comparar casos (inclusive com outras maneiras), principalmente devido à restringência de cada uma (mais e menos restritiva, respectivamente).

O perigo dessa abordagem é atribuir muita representatividade aos casos e sair do estudo de caso para um estudo de múltiplas unidades, perdendo a profundidade e detalhamento inerente aos primeiros. Existe, também, a dificuldade de encontrar casos passíveis de serem comparados. Por outro lado, dá uma maior possibilidade de extrapolação e por vezes é mais simples de aplicar por haver um roteiro de questões a seguir e aplicar para todos os casos.

A despeito de suas desvantagens e limitações, os cinco métodos de análise descritos aqui poderão ser muito úteis ao pesquisador na correta aplicação da metodologia de estudo de caso para investigar temáticas relacionadas às políticas ambientais. Porém, antes de destacar suas vantagens para essa subdisciplina, é preciso primeiro discutir por que o estudo da interface política-meio ambiente necessita de atenção especial quanto à metodologia aplicada, enfoque da seção a seguir.

\section{O ESTUDO DA POLÍTICA AMBIENTAL: DISTINÇÃO DE OUTRAS SUBDISCIPLI- NAS}

Nacional ou internacionalmente, inúmeros fatores ambientais podem influenciar os sistemas político-sociais e requerer instrumentos políticos, como situações transfronteiriças, áreas comuns que abrigam recursos naturais e interligações entre diferentes temas da questão ambiental. Por isso, é difícil separar onde começa e termina a importância política dos diferentes temas ambientais, dada sua complexidade e sobreposição. São vários os tópicos relevantes para estudo: políticas públicas de meio ambiente, regimes internacionais de desenvolvimento sustentável, accountability de

2 Todos os trechos reproduzidos no presente artigo foram traduzidos dos originais pela própria autora. instituições ambientalistas do terceiro setor, refugiados ambientais, conflitos decorrentes de escassez ambiental, questões do tipo "tragédia dos comuns", entre outros. De fato, vários autores acreditam que abordagens metodológicas específicas ou mesmo novas são necessárias para pesquisar a interface política-meio ambiente (ver, por exemplo, SUNDGREN, 1993; YOUNG, 1994; HOMERDIXON, 1996). Nesta seção trataremos das principais dificuldades de abordar temáticas ambientais dentro da Ciência Política e o porquê da necessidade de cuidados metodológicos específicos. Para tal, discute-se o paradoxo da dicotomia ser humano-natureza e certos desdobramentos ontológicos e epistemológicos, alguns desafios conceituais das pesquisas em política ambiental e as implicações do tipo de informação escolhida para ser analisada nesse tipo de estudo.

Tratar de questões ambientais em um contexto político traz à tona um paradoxo: o ser humano, ao mesmo tempo em que faz parte do meio ambiente, percebe-se separado dele. Ou seja, apesar da inevitável interdependência entre o Homo sapiens sapiens e o meio, a grande maioria das sociedades humanas historicamente enxerga-se como um grupo de seres "separados" da "natureza" ou mesmo superior e senhor desta (WHITE JR., 2000) ${ }^{3}$. Essa dicotomia está presente, inclusive, na academia; de fato, há autores que afirmam que as Ciências Sociais desenvolveram-se sobre uma "rígida dicotomia entre cultura e natureza" (FITZGERALD, 2006, p. 1) ${ }^{4}$. Esse é um debate antigo e não é intenção deste artigo retomálo; porém, é imprescindível que o pesquisador esteja ciente dessa discussão para que (1) possa deixar claro seu posicionamento ontológico e epistemológico ao realizar qualquer pesquisa sobre política ambiental e (2) saiba que há a possibilidade da própria percepção dos atores envolvidos no caso em estudo tenha influência sobre o problema em foco. Esses pontos podem fazer os estudos em política ambiental parecerem demasiado difíceis de realizar, mas isso não precisa ne-

3 White Jr. (2000) discute a origem judaico-cristã da dicotomia ser humano-natureza; para uma revisão de outros pontos de vista sobre essa origem, ver Fernandes e Sampaio (2008).

4 Ver também as relevantes discussões de Descola e Pálsson (1996) e Foster (2005); nesta última obra destaca-se o primeiro capítulo, "A concepção materialista de natureza" (idem, p. 39-96). 
cessariamente ser verdade. Sobre o primeiro ponto, como já foi dito, a importância está em ter um posicionamento claro no momento da estruturação da pesquisa, bem como na hora de sistematizar e publicar os resultados. Ou seja, considera-se, como ponto de partida, a dicotomia ser humanonatureza ou uma perspectiva mais integrada? A partir da resposta dessa e de outras perguntas possíveis é preciso decidir como lidar com o segundo ponto ou mesmo (explicitamente) ignorá-lo.

Questões conceituais também devem ser levadas em consideração ao estudar o meio ambiente em um contexto político. Choucri (1993) lista três desafios conceituais para a Ciência Política, originados nas mudanças ambientais globais: o desafio da ligação (linkage), o desafio das políticas e o desafio institucional. Esses desafios sinalizam a necessidade de aprofundar o conhecimento sobre as ligações, interligações e processos de feedback na complexa biosfera terrestre e todas as implicações resultantes.

O primeiro desafio trata de como relacionar as variáveis e processos ambientais (interações climáticas, interdependência dos ecossistemas, ciclos biogeoquímicos, biodiversidade, entre outros) às questões sócio-políticas (atividades sociais, características nacionais, relações internacionais, soberania, etc.); segundo Rosenau (apud CHOUCRI, 1993, p. 9), essas ligações ocorrem em qualquer momento que uma atividade em um sistema afete as condições de outro sistema, subsistema ou ambiente. Já o desafio das políticas, estaria em desenvolver definições e abordagens apropriadas para referir-se ao manejo do commons global, tendo como dado o fato do bemestar do planeta e seus habitantes ser afetado diretamente pelo comportamento dos indivíduos, países, instituições etc. Por fim, o desafio institucional seria como identificar respostas institucionais apropriadas para lidar com as mudanças antrópicas no ambiente.

Entretanto, é importante destacar que o primeiro desafio citado por Choucri (idem) também remete a duas outras questões com implicações conceituais: a primeira, já mencionada, seria a própria percepção que o ser humano tem do meio ambiente, a começar pela dicotomia ser humanonatureza ou meio ambiente-sociedade; o segundo caso refere-se a uma controvertida noção de equilíbrio ecológico. É comum, salvo entre os meios acadêmicos que tratam de ecologia pura, a visão de que os ecossistemas saudáveis permaneçam em uma espécie de "equilíbrio estático" até que o homem venha e cause um "desequilíbrio"5; por esse motivo, alterações não antropogênicas no ambiente (e suas interações com o impacto antrópico) são freqüentemente deixadas de lado em estudos que lidam com a interface meio ambiente-sociedade.

Outra questão pertinente ao estudo das políticas ambientais é que tipo de dados será avaliado para responder as indagações da pesquisa: indicadores puramente biológicos, efeitos políticos observáveis ou uma mistura de ambos? Optar por quaisquer desses três tipos de dados traz conseqüências que precisam ser levadas em consideração para avaliar a viabilidade da pesquisa. No primeiro caso é preciso verificar a disponibilidade e confiabilidade dos dados biológicos. Helm e Sprinz (2000), em trabalho teórico sobre a eficácia dos regimes ambientais, destacam que as pesquisas nessa área podem tornar-se mais lentas devido à carência de dados biológicos e/ou pelo longo período de tempo necessário para a recuperação do problema em estudo. Mesmo quando há dados disponíveis, Rosendal (2000) aponta para a dificuldade de mensurar sucessos obtidos em relação a problemas político-ambientais globais. Nesse sentido, autores como Keohane, Haas e Levy (1993) sugerem optar pelo segundo grupo de dados, enfocando os efeitos políticos observáveis das instituições e não o impacto ambiental em si. De acordo com esses autores, tais efeitos podem ser observados pelo desempenho das próprias instituições: "instituições eficazes podem afetar o processo político em três pontos-chave na seqüência de criação e implementação de políticas ambientais: 1) Podem contribuir para agendas mais apropriadas, refletindo a convergência de consensos políticos e técnicos sobre a natureza das ameaças ambientais; 2) podem contribuir para políticas internacionais mais detalhadas e específicas, acordadas por meio de um processo político cuja base é a negociação intergovernamental; 3 ) podem contribuir para a criação de políticas nacionais em resposta ao problema que controlem as fontes de degradação ambiental diretamente (idem, p. 8).

Similarmente, Homer-Dixon (1993) afirma que estudos sobre política ambiental trazem em si uma série de incertezas que dificultam a análise das

5 A esse respeito, ver a interessante discussão de Mazotti (1997). 
variáveis, e lista alguns dos fatores que contribuem para o nível dessas incertezas: qualidade da teoria utilizada, qualidade e quantidade de dados, dúvidas sobre a habilidade de resposta antrópica ao problema e processos caóticos. Ademais, salienta que grande parte do mundo socioambiental ${ }^{6}$ integra sistemas caóticos e imprevisíveis que, portanto, não possuem relações lineares. A capacidade de resposta dos seres humanos à degradação ambiental seria outro ponto problemático, mesmo porque é freqüente que as pessoas sequer queiram mudar os processos sociais, econômicos, tecnológicos e outros fatores que contribuam para esse quadro. De fato, em outro momento Homer-Dixon (1996) afirma que os estudos sobre a escassez ambiental e sua relação com conflitos sociais caracterizam-se "por um número imenso de variáveis desconhecidas e conexões causais desconhecidas entre estas variáveis, por interações, feedback e relações nãolineares e por uma alta sensibilidade a pequenas perturbações" (idem, p. 134). De modo geral, podese dizer que isso se aplica a todas as questões político-ambientais, o que deve ser levado em consideração no desenho metodológico desse tipo de estudo. Entretanto, mais uma vez salienta-se que esses fatores não devem impedir a realização de estudos sobre política ambiental, mas sim reforçar os cuidados e escolhas metodológicas. Uma saída referente a esta última discussão seria optar por analisar os efeitos políticos observáveis (conforme sugerido por Keohane, Haas e Levy (1993)) no caso de temas com poucos dados ou variáveis muito incertas, enquanto um maior enfoque nos dados biológicos poderia ser utilizado em casos com maior disponibilidade e confiabilidade desse tipo de informação.

Obviamente, como os sistemas político-ecológicos, a maioria dos objetos de estudo da Ciência Política também é de extrema complexidade. Porém, viu-se nesta seção que no caso específico das políticas ambientais é imprescindível levar em consideração três questões principais: implicações ontológicas e epistemológicas acerca da dicotomia ser humano-natureza e sua percepção; desafios conceituais relativos a linkage, manejo dos recursos globais e instituições; e a escolha do tipo de dados a ser analisado. A partir de tais considerações o pesquisador poderá utilizar a metodologia 6 Acerca do termo "socioambiental" ver, por exemplo, a
discussão de Fernandes e Sampaio (2008). de estudo de caso de maneira sólida, conforme veremos na próxima seção.

\section{VANTAGENS E LIMITAÇÕES DO USO DE ESTUDOS DE CASO NA PESQUISA SOBRE POLÍTICAAMBIENTAL}

Foi visto que o estudo de caso é um tipo de metodologia com várias vantagens e desvantagens, bem como alguns métodos de análise de interesse para a Ciência Política, cada qual com suas limitações próprias. Ademais, vimos que considerações específicas às questões político-ambientais precisam ser levadas em conta na hora de projetar-se estudos a respeito. Nesta seção abordaremos o uso da metodologia de estudo de caso (e das formas de análise e extração de inferências descritas anteriormente) em pesquisas sobre política ambiental; para isso, discutiremos algumas das ambigüidades do método e sua relevância para o tema, além de ressaltar vantagens e limitações dos estudos de caso e cinco de suas formas de análise no contexto da política ambiental.

Devido à natureza diferenciada do tema, Mitchell e Bernauer (1998) reconhecem que as pesquisas sobre a política ambiental (mais especificamente a política ambiental internacional) têm maior necessidade de utilizar a metodologia de estudo de caso, principalmente no que diz respeito à análise e avaliação de inferências causais. Entretanto, salientam que é preciso seguir seis passos-chave para que essas pesquisas tenham boa qualidade: 1) identificar uma questão teórica importante; 2) desenvolver hipóteses e identificar variáveis; 3) selecionar casos; 4) ligar dados a propostas; 5) examinar correlações e rotas causais; 6) generalizar para outros casos. Os autores também sugerem que os estudos sobre política ambiental respeitem cinco critérios principais. 1) Validade teórica. As informações empíricas reunidas representam, verdadeiramente, os conceitos ou variáveis do modelo teórico proposto ou do caso em estudo? 2) Validade interna. O método analítico mostra a correlação entre a variável independente e a variação observada na variável dependente para cada hipótese de relação causal, de maneira que nenhuma outra variável (ou variáveis) fornece uma explicação melhor sobre a variação observada? 3) Validade externa. Está claro o limite entre a população de casos para a qual generalizações podem ser feitas e outros casos para os quais estas generalizações são improváveis? 4) Confiabilidade. Outros pesquisadores poderia replicar as técnicas utilizadas na pesquisa e chegar 
aos mesmos resultados? 5) Status de pesquisa progressista. $\mathrm{O}$ estudo contribui, de maneira cumulativa para um programa de pesquisa maior?

Dessa forma, esses estudos devem tentar responder uma questão empírica específica, bem como uma questão teórica maior. Ao lado desses passos e critérios, deve levar-se em consideração alguns outros fatores na hora de conceituar um estudo desse tipo, como as ambigüidades inerentes ao método e sua relevância para pesquisas sobre política ambiental.

\section{IV.1. O problema das ambigüidades}

De acordo com Gerring (2004), os estudos de caso trazem seis ambigüidades inerentes que podem ser problemáticas, dependendo da forma como se lida com as mesmas: 1) é possível construir tais estudos com diferentes tipos de evidência covariante, visto que alguns estudos de caso envolvem mudanças de nível de análise e outros mesclam diferentes tipos de observação sobre ou dentro da mesma unidade, caracterizando tipos de estudo de caso distintos; 2) existe uma linha tênue entre a unidade em foco (a unidade formal) e outras unidades adjacentes que possam ser incluídas no estudo de maneira mais solta (as unidades informais); 3) é comum que vários estudos de caso sejam reunidos em um único estudo (ou seja, mais de uma unidade é analisada, caracterizando outro tipo de metodologia); 4) comumente, engloba-se dois mundos empíricos distintos (da unidade em si e de uma classe mais ampla de unidades) e, conseqüentemente, os resultados do trabalho passam a aplicar-se a populações diferentes; 5) o status do trabalho é passível de mudar após ser analisado mais profundamente pela comunidade científica; 6) as inferências do estudo podem ser ilustrativas ou falsificáveis.

Tomando essa lista como base, pode-se analisar o impacto dessas ambigüidades nas pesquisas sobre política ambiental. A primeira ambigüidade, que lida com a questão dos níveis de análise e/ou tipos de observação dentro da unidade em análise (resultando em diferentes tipos de evidência covariante), é um problema real dentro das pesquisas nessa área. Ao longo dessa seção utilizaremos como exemplo a análise hipotética de um regime ambiental global, a Convenção Internacional para a Regulamentação da Pesca da Baleia (Cirpb). Neste caso, o estudo poderia analisar desde o impacto do tratado na diversidade genética de populações locais de baleias, até a cooperação entre países para a troca de informações sobre pesquisas realizados acerca do estado de determinada espécie. Similarmente, Choucri (1993) lista quatro níveis de análise possíveis em um estudo sobre política internacional ambiental: 1 ) as decisões individuais (p. ex.: pescar ou não pescar baleias); 2) as decisões organizadas de grupos sociais dos mais diversos (escolha de uma colônia de pescadores ou empresa de pesca de respeitar ou não o tratado internacional citado e continuar ou descontinuar a capturar baleias); 3) o sistema internacional competitivo e seus mecanismos institucionais de tomada de decisão (a decisão de cada país em ratificar ou não a convenção); 4) o sistema global natural e social, completamente interligado por processos de feedback altamente dinâmicos (a relação das espécies de baleias capturadas com toda a biosfera e sua própria resiliência em face da caça). Por outro lado, como lembra Gerring (2004), essa ambigüidade é relativamente fácil de evitar com a redação de projetos de pesquisa com objetivos precisos e delimitação clara da unidade a ser estudada; a unidade, os casos e as populações, por exemplo, devem estar bem definidos para dar maior credibilidade e maior nível de falseabilidade ao trabalho. Isso não elimina a possibilidade de realizar observações em diferentes níveis de análise caso entenda-se como relevante; porém, é imprescindível deixar claro o enfoque do estudo tanto para o próprio pesquisador quanto para os colegas que irão ler e utilizar seu trabalho como base para outras pesquisas. $\mathrm{Ou}$ seja, a unidade estudada poderia ser a eficácia da Cirpb e os casos seriam alguns países signatários, em meio a uma população que incluiria todos as partes do acordo.

Esse problema está ligado à segunda ambigüidade, que mostra a tênue linha entre a unidade que está sendo enfocada e outras unidades adjacentes que possam ser relevantes (ou seja, unidades informais). Mais uma vez é necessário que isso esteja claro na pesquisa, o que se traduzirá na forma como o estudo é conduzido: enquanto a unidade formal deve ser analisada de maneira intensiva e aprofundada, as unidades informais podem ser analisadas por meio de literatura secundária, por exemplo, e discutidas fora do corpo central do texto, como na introdução ou nas conclusões (idem). Aqui cabe retomar a discussão sobre as implicações dos tipos de dados usados na análise. Digamos, por exemplo, que não houvesse dados científicos suficientes sobre o estu- 
do das populações de baleia, ou que essas informações não fossem homogêneas para todas as partes do mundo onde esses animais ocorrem. Nesse contexto, uma forma de realizar o estudo sem cair nas armadilhas da segunda ambigüidade seria analisar a unidade formal (digamos que fosse mesmo a eficácia da convenção) usando como dados os efeitos políticos observáveis da Cirpb, como criação de instrumentos legais e/ou novos órgãos governamentais para cuidar do assunto, estímulo à pesquisa por meio de novas linhas de fomento, programas educativos para as comunidades baleeiras etc. Por outro lado, as unidades adjacentes poderiam incluir as conseqüências do regime $^{7}$; como não haveria a necessidade de avaliações mais aprofundadas poder-se-ia, neste caso, utilizar os escassos dados biológicos disponíveis.

Em um exemplo semelhante, digamos que em determinado país a pesca desse animal tenha caído drasticamente após a ratificação da Cirpb e que haja dados biológicos que comprovem a recuperação das populações de baleias. A pergunta central, neste caso, seria o porquê da convenção ter sido eficaz naquele país, enquanto a unidade formal de análise seria a eficácia da convenção e o caso seria o país escolhido. Poder-se-ia usar, também, outros países (casos) onde a convenção não foi eficaz ou funcionou apenas parcialmente. Neste contexto, poderia se estudar os relatórios enviados para a Organização das Nações Unidas (ONU), as políticas públicas criadas como resultado da convenção ou mesmo criar contrafatuais sobre como estaria a situação baleeira no(s) país(es) enfocado(s) se o regime não tivesse sido implementado. Porém, outras unidades (ou seja, unidades informais) também poderiam ser estudadas de maneira mais periférica, tais como a eficácia da Convenção das Nações Unidas sobre o Direito do Mar e sua influência na regulamentação da pesca da baleia naquele(s) país(es).

Relembrando o terceiro passo-chave promovido por Mitchell e Bernauer (1998), estes autores salientam a importância do processo de seleção dos casos a serem estudados, que somente

7 De acordo com Zürn (1998), o estudo das conseqüências de um regime enfoca os resultados mais amplos do ato estabelecido, não necessariamente intencionais ou alinhados com os objetivos do mesmo, enquanto Underdal (1992) define o estudo da eficácia dos regimes como uma avaliação comparativa de um acordo contra algum padrão de sucesso ou realização. deverá ocorrer após o devido embasamento com as teorias disponíveis. Nesse sentido, afirmam que jamais se deve permitir que os casos direcionem os questionamentos da pesquisa: "Na maioria dos casos, questões teoricamente 'quentes' não podem ser respondidas usando casos politicamente quentes. [...] estudos de 'temas-manchete' [sobre a eficácia dos regimes] resultarão em pouco ou nenhum conhecimento sobre como projetar acordos internacionais para induzir a melhoria ambiental simplesmente porque os dados necessários para identificar as fontes de eficácia nesses casos ainda não estão disponíveis" (idem, p. 14-15).

A terceira ambigüidade refere-se às situações em que vários estudos de caso são reunidos em um estudo maior, analisando-se mais de uma unidade. À primeira vista não haveria problema, porém Gerring (2004) salienta que quanto mais casos há para estudar-se, menor o aprofundamento dado em cada caso. Ademais, o autor afirma que se o pesquisador acredita que os casos utilizados são muito representativos, passará a tratar o conjunto de casos mais como uma amostra do que como uma série de casos individuais. A despeito das pesquisas político-ambientais, essa ambigüidade poderá ter maior ou menor importância dependendo do assunto tratado. Além disso, se não houver muita informação disponível, é preferível priorizar um estudo de caso individual, analisando-o de maneira mais intensiva (como no exemplo anterior, em que havia dados biológicos aprofundados sobre a população de baleias de um único país).

A quarta ambigüidade, que trata dos mundos empíricos distintos comumente englobados por um único estudo de caso (ou seja, o mundo da unidade em si e de uma classe mais ampla de unidades), está intimamente ligada ao sexto preceito listado por Mitchell e Bernauer (1996). Estes autores afirmam que os resultados dos estudos de caso devem ser generalizáveis para outros casos; porém, Gerring (2004) chama a atenção para o problema de ter-se um trabalho cujos resultados apliquem-se, contraditoriamente, a populações completamente diferentes. Apesar das generalizações serem desejáveis quando possível, o pesquisador precisa tomar cuidado para não ser ambicioso demais. Segundo Mitchell e Bernauer (1996), o escopo da generalização dependerá no nível de validade externa do trabalho; ou seja, quanto mais semelhantes as relações causais do caso estudado com amostras de casos maiores, maior a chance 
de encontrar conexões válidas com debates teóricos mais amplos. De fato, esses autores ressaltam que muitas teorias gerais sobre relações internacionais, por exemplo, servem também para explicar problemas político-ambientais globais.

Por outro lado, é relativamente comum que os pesquisadores da área de política ambiental sejam cautelosos demais na hora de extrapolar seus resultados para debates mais gerais. Apesar de a área estar em constante crescimento dentro da Ciência Política, ainda é pouco estudada em comparação a outros temas e até mesmo marginalizada ou ignorada. Porém, muitos dos resultados de suas pesquisas e suas conseqüentes contribuições teóricas têm muita relevância para outros debates mais amplos, e poderiam ser melhor aproveitados na Ciência Política de modo geral. Um exemplo clássico de sucesso é o trabalho de Haas (1989) sobre regimes de controle de poluição marinha no Mediterrâneo, citado com freqüência até os dias de hoje no debate sobre a famosa questão " $D o$ regimes matter?" (“Os regimes importam?").

A quinta ambigüidade dos estudos de caso traz a possibilidade de o status do trabalho mudar após uma análise mais intensiva pela comunidade científica. Um exemplo é o das revisões de literatura, que podem tentar unir vários estudos de caso $\mathrm{e}$ analisá-los conjuntamente, formando uma grande amostra. O perigo desse tipo de prática dependerá do assunto em questão, bem como da similaridade entre os casos e de sua validade externa comum. Em estudos ligados à política ambiental deve haver cautela em como isso deverá ser feito. Um exemplo de sucesso é a compilação de Miles et alii (2002), que reúne vários estudos sobre a eficácia de diversos regimes ambientais. Os autores foram muito cuidadosos ao agrupar os estudos em três classificações, baseadas na eficácia do acordo enfocado: regimes eficazes, mistos e de baixa eficácia, além de um regime controle fora da área ambiental. Mitchell (2006), por outro lado, ressalta a importância de levar em conta a estrutura do problema ambiental ao pesquisar a eficácia desse tipo de $\operatorname{acordo}^{8}$, e a mesma pode, inclusive, moldar a forma como os estados o percebem e montam seus objetivos em termos de mu-

8 De fato, alguns autores já tentaram usar escalas para classificar regimes ambientais, como Underdal (2002), que argumenta por um agrupamento dos problemas ambientais internacionais em três classes ("benigno", "maligno" ou "misto"), de acordo com a estrutura do problema. danças comportamentais e resolução dos problemas ambientais em si, com soluções mais superficiais ou mais aprofundadas. Por exemplo: um comportamento nocivo ao meio ambiente pode ser banido ou apenas restringido e o uso de uma espécie pode ser proibido completamente, restrito ou apenas manejado.

A última ambigüidade que discutiremos talvez seja a mais importante: a do status ilustrativo ou falsificável das inferências resultantes dos estudos de caso. O primeiro caso (bastante comum nos estudos sobre política ambiental, principalmente os pioneiros) advém de estudos com enfoque mais descritivo e com pouca pretensão de generalizar os resultados para outros casos ou para debates teóricos mais amplos; estudos muito importantes para temas com histórico recente e/ ou poucos dados disponíveis. Um bom exemplo é o da Convenção sobre Diversidade Biológica (CDB). Talvez devido à sua natureza ambiciosa, profundamente política e de amplo espectro (LE PRESTRE, 2002, p. 269), a CDB é um dos regimes ambientais menos estudados politicamente, principalmente em termos de sua eficácia. Um dos poucos pesquisadores a abordar este assunto foi Le Prestre (idem; 2003), em estudos principalmente descritivos. Além de ser um regime relativamente recente, em vigor desde 1993, apresenta uma série de desafios para a pesquisa devido à falta de dados científicos e indicadores de biodiversidade biológica. Assim, os achados de Le Prestre são muito importantes para pesquisas subseqüentes por fornecer subsídios para um maior aprofundamento do assunto, como sugestões preliminares que mais tarde poderão ser pesquisadas mais detalhadamente.

Contrariamente aos estudos de caráter ilustrativo ou sugestivo, existem estudos de caso que resultam em novas hipóteses ou teorias robustas e passíveis de ser falsificáveis. Como lembra Gerring (2004), ambos partem de bases metodológicas completamente distintas. Por outro lado, aponta para a vantagem de usar os estudos de caso no último caso. Afinal, a flexibilidade do próprio método é, em muitos sentidos, superior às pesquisas mais "formais" ou quantitativas, que muitas vezes ficam presas à sua própria rigidez e conseguem apenas confirmar ou falsificar outras teorias e hipóteses: “[...] a própria 'subjetividade' das pesquisas de estudo de caso permite a geração de um grande número de hipóteses e percepções que talvez não ficariam aparentes ao pes- 
quisador de múltiplas unidades que trabalha com um conjunto de dados empíricos mais superficial de um grande número de unidades e com uma definição mais determinada (fixa) de casos, variáveis e resultados. É a própria difusibilidade dos estudos de caso que lhes dá uma forte vantagem nas pesquisas em estágios exploratórios, pois os estudos de uma única unidade permitem o teste de uma multiplicidade de hipóteses de maneira rápida e informal" (idem, p. 350). Essa flexibilidade do método representa uma vantagem a mais para os estudos de caso em política ambiental, dada a freqüente carência de dados e indicadores biológicos.

\section{IV.2. Vantagens e limitações gerais para estudos sobre política ambiental}

Uma das principais vantagens do uso da metodologia de estudos de caso para questões ambientais é a possibilidade de identificar variáveis e hipóteses novas ou omitidas que podem servir de base para outros estudos e/ou para a construção de novas hipóteses e teorias. Apesar dessa vantagem não ser, necessariamente, peculiar às questões ambientais, é muito útil em situações em que é preciso realizar pesquisas iniciais ou exploratórias por falta, por exemplo, de dados biológicos. Na mesma linha, o trabalho de Yin (2009) sobre estudos de caso em geral já sugere sua importância para a temática político-ambiental quando afirma que o método é apropriado para situações em que o pesquisador tem pouco controle, quando os limites do fenômeno e de seu contexto não estão claros e cujo enfoque está em algum fenômeno contemporâneo. Outra vantagem ainda pouco aproveitada é a capacidade de usar a flexibilidade do método para criar novas hipóteses e teorias e suprir carências nesse sentido. Essas novas hipóteses e teorias passíveis de serem testadas subsidiam, assim, outros estudos de caso de caráter mais confirmatório/contraditório, visto que muitas abordagens requerem a pré-existência de boas teorias para que possam prover explicações mais completas.

De fato, existe uma limitação nos casos em que não existam teorias específicas para a temática político-ambiental (ou nenhuma teoria geral que se aplique), visto que muitas das abordagens possíveis possuem como pré-condição a disponibilidade de teorias robustas de embasamento. Outro problema é a dificuldade de escolher casos relevantes e generalizáveis, o que nem sempre é possível.
Por outro lado, é importante salientar que, da mesma forma que os estudos de caso complementam outros tipos de pesquisa, as diversas formas de análise e extração de inferências também podem ser utilizadas de maneira complementar nos estudos de caso sobre a interface política-meio ambiente.

\section{IV.3. Vantagens e limitações das abordagens es- pecificas}

Anteriormente, descrevemos cinco abordagens utilizadas para realizar inferências nos estudos de caso, a saber: análises de covariância, process tracing causal, uso de contrafatuais, testes de congruência e comparação de casos. Debateremos a seguir as vantagens e limitações destas abordagens especificamente para as pesquisas sobre política ambiental.

As análises de covariância trazem várias vantagens para os estudos de caso com enfoque em interfaces político-ambientais. Sua semelhança com experimentos controlados favorece os casos onde as conseqüências políticas da degradação ambiental estão fortemente ligadas a fatores naturais mais fáceis de contabilizar (p. ex.: efeito da chuva ácida no desempenho agrícola e conseqüente impacto político). Outra vantagem é não ter de realizar observações empíricas de todo processo causal, sendo possível extrair conclusões abstratas originadas da teoria que está sendo utilizada como base. Porém, essa vantagem pode transformar-se em uma limitação caso não existam teorias disponíveis. Nesse caso, pode-se tentar procurar teorias mais amplas, fora do campo ambiental, para serem usadas na abordagem.

O método de process tracing, bem mais distante do desenho quase experimental das análises de congruência e dos testes de congruência, talvez seja a abordagem de maior sucesso nas pesquisas sobre política ambiental. Existem vários exemplos de bons estudos de caso, nessa área, que utilizaram process tracing causal como forma de análise, e que inclusive serviram de base para volumes inteiros na área de política internacional ambiental: Haas (1989) compila uma série de estudos que aplicaram, com sucesso, análises causais para investigar a eficácia das instituições internacionais em relação a sete questões ambientais, complementadas por análises rigorosas de contrafatuais hipotéticos; Victor et alii (1998) editam um livro sobre a implementação e eficácia de tratados internacionais de meio ambiente que 
inclui 14 estudos de caso que utilizam esta abordagem; por fim, Rosendal (2000) utiliza process tracing para analisar o processo de implementação de um regime ambiental, em um volume sobre a Convenção sobre Diversidade Biológica (CDB) que enfoca os países em desenvolvimento.

Para compreender como uma análise de process tracing causal de um fenômeno político-ambiental funciona na prática, exemplificaremos com um estudo por Kotov e Nikitina (1998) sobre a implementação e eficácia de um regime sobre chuva ácida na Rússia, a Convenção sobre a Poluição Atmosférica Transfronteiriça a Longa Distância. Estes autores realizaram uma análise aprofundada de diversos aspectos da convenção no país, principalmente o histórico do regime (inclusive sua implementação doméstica e os níveis de compliance nacional) e os efeitos comportamentais do acordo em diversas áreas. Assim, puderam traçar uma história completa sobre a causa e o efeito do processo em foco, concluindo que o regime estudado teve maior importância política para a Rússia que eficácia ambiental propriamente dita.

É importante lembrar que neste caso, o uso de process tracing foi possível devido à escolha de um regime com um histórico relativamente longo (a convenção enfocada, que possui também oito protocolos, foi assinada em 1979 e ratificada em 1983); ademais, os autores tiveram o cuidado de não confundir instâncias de correlação com relações verdadeiras de causa e efeito, distinguindo os processos de implementação e compliance do regime (VICTOR et alii, 1998). Afinal, uma das principais limitações da abordagem de process tracing é a grande quantidade de dados necessários para construir a cadeia causal de onde as inferências serão extraídas. Na prática, isso se traduz em um esforço de campo grande (e muitas vezes custoso) para o pesquisador, ou mesmo na impossibilidade de realização quando as informações necessárias não são suficientes em quantidade e/ou profundidade. Assim, é um método mais apropriado para temas de pesquisa com histórico suficientemente longo e bem documentado; a eficácia de regimes ou políticas públicas recém implementadas, por exemplo, dificilmente se beneficiariam desta abordagem.

Um exemplo relevante, delineado por HomerDixon (1996) é o do estudo de causa e efeito em sistemas político-ecológicos complexos que levam à violência devido à escassez ambiental; neste caso, o autor defende que a maioria dos princípios metodológicos utilizados na Ciência Política são inapropriados para este tipo de pesquisa devido à pouca compreensão que se tem dos sistemas políticos-ecológicos. Assim, advoga uma pluralidade metodológica que deve se iniciar com o uso de process tracing causal e passar para outros métodos de acordo com cada estudo. Por outro lado, este autor salienta que o conceito de causalidade é impreciso, principalmente nos estudos que mesclam variáveis sociais e ambientais, o que deve ser levado em consideração na hora de traçar o procedimento metodológico. Uma alternativa apontada seria enfocar não apenas a causa mas também o efeito, em uma relação caracterizada por sete variáveis: necessidade, força, proximidade, "exogeneidade", multicausalidade, interatividade e não-linearidade. Ademais, salienta a importância do método escolhido para testar as hipóteses; segundo ele, é preciso ir além dos modelos utilizados nas ciências naturais para obter uma compreensão mais aprofundada das questões político-ecológicas (HOMER-DIXON, 1996).

O uso de contrafatuais é talvez a forma mais promissora de extrair inferências sobre o mundo político-ambiental, já tendo sido usado com sucesso em vários estudos. Além dos estudos compilados por Haas (1993) mencionados anteriormente, podemos citar: Mitchell (1994), em estudo sobre o cumprimento de dois regimes relativos à poluição marinha por petróleo (como estariam os níveis de conformidade com sem as mudanças de regras?); a série de estudos sobre a eficácia de regimes internacionais de meio ambiente compilados por Miles et alii (2002); alguns dos estudos do volume sobre a implementação e eficácia de acordos ambientais compilado por Victor, Raustiala e Skolnikoff(1998), entre outros. Uma de suas grandes vantagens é a possibilidade de delinear explicações, criar hipóteses e até mesmo teorias quando não há grandes quantidades de informações e/ou casos observáveis no mundo real. Por outro lado, não pode ser realizado de maneira solta, sem embasamento teórico: as análises de contrafatuais de boa qualidade devem levar em conta as teorias disponíveis.

Para uma melhor compreensão do uso desse método na área político-ambiental, utilizaremos como exemplo o estudo de Wettestad (2002) sobre os regimes que tratam da destruição da camada de ozônio, a chamada Convenção de Viena e seu respectivo Protocolo de Montreal. Nesse trabalho, o autor analisa dois pontos de vista opostos: 1) qual a melhoria relativa da situação da camada de ozô- 
nio usando como base um cenário sem a existência da convenção; 2) qual a distância de um ótimo coletivo ideal. No primeiro caso, analisa a questão do cumprimento (compliance) baseado nas evidências palpáveis, bem como a possível influência de outros instrumentos implementados na mesma época. No caso do coletivo ótimo, utiliza as recomendações científico-tecnológicas e políticas existentes, não sem questionar suas limitações devido à falta de dados completos. Baseado nesses dois contrafatuais, bem como em outros tipos de análise (principalmente histórica), conclui que os acordos estudados foram altamente eficazes por terem causado mudanças comportamentais significativas, principalmente nos países do Norte. Porém, vale salientar que a natureza do problema em questão facilitou o uso de contrafatuais no estudo; apesar da complexidade do problema da camada de ozônio, a fonte de degradação restringe-se a uma quantidade relativamente pequena de substâncias produzidas em um grupo reduzido de países. Uma questão como a das mudanças climáticas, por exemplo, certamente seria mais complicada de analisar dessa forma, devido à quantidade ainda maior de variáveis envolvidas.

Semelhante às análises de covariância, os testes de congruência permitem realizar análises qualitativas relativamente "controladas" e possuem vantagens e limitações parecidas. Porém, conforme mostrado anteriormente, permitem extrair predições mais diversificadas por não se limitar à covariância das variáveis verificando a congruência (ou não) entre as observações realizadas e as predições que o pesquisador construiu a partir das teorias disponíveis (BENNETT, 2004; BLATTER \& BLUME, 2007; 2008b). Assim, como no caso das análises de covariância, é preciso haver teorias robustas disponíveis, bem como dados palpáveis, para a realização dos testes. Nesse sentido, é um método bastante interessante para casos com disponibilidade de índices e outros indicadores socioambientais

Na prática, podemos exemplificar os testes de congruência com um estudo que analisa a regulamentação ambiental relativa ao lago de Constança, um corpo de água transnacional localizado na Alemanha, Áustria e Suíça. Discutindo desde teorias racionalistas até enfoques sócio-construtivistas, o autor testa a congruência das expectativas em torno da gestão conjunta do lago, unindo essas discussões com dados empíricos dos órgãos regulatórios e comparações com outros casos re- levantes, além de verificar os valores das variáveis independentes. Ao final, conclui que existe um mecanismo causal por trás do desempenho das regulamentações ambientais da área que vai além da problemática e contexto do próprio lago (BLATTER, 2004).

Por fim, a comparação entre casos (estudo de caso múltiplo) é outra abordagem freqüentemente usada nos estudos de caso sobre política ambiental. É preciso cautela na hora de comparar os casos para evitar erros inferenciais e, antes de mais nada, é necessário deixar claro o que está sendo comparado. Existem várias possibilidades comparativas em um estudo sobre regimes ambientais, por exemplo, em que o enfoque pode ser: a eficácia do regime em diversos países, o processo de implementação de diferentes regimes, o nível de compliance dos países-membros de uma determinada convenção, entre outros. Nesse sentido, apesar de não ser um estudo de caso comparativo per se por reunir vários estudos de caso, o livro compilado por Miles et alii (2002), sobre a eficácia de regimes ambientais, dá uma idéia interessante das possibilidades dos estudos de caso. Tentando responder por que algumas convenções são eficazes e outras não, compara 14 estudos de caso, classificando-os em três grupos: regimes eficazes, regimes de baixa eficácia e regimes mistos.

Nessa abordagem há o perigo de atribuir muita representatividade aos casos, perdendo a profundidade e detalhamento inerente aos estudos de caso, bem como a dificuldade de encontrar casos passíveis de serem comparados na área políticoambiental. Por outro lado, permite uma maior possibilidade de extrapolação, o que nem sempre é possível aos estudos de caso em política ambiental. Também há uma maior facilidade de aplicar teorias mais abrangentes de outras áreas quando não há teorias específicas às questões políticoambientais. Outra vantagem é a possibilidade de criar teorias tipológicas, de grande valia na área.

Dentre as cinco abordagens discutidas (cujas vantagens e desvantagens são resumidas no Quadro 2), duas destacam-se das demais para uso nas pesquisas político-ambientais: process tracing e uso de contrafatuais. A primeira pela possibilidade de realizar estudos detalhados e ao mesmo tempo abrangentes, construindo uma cadeia completa de causa e efeito. Já a segunda abordagem é extremamente útil em casos recentes e com poucos dados, como os problemas ambientais que têm surgido 
nas últimas décadas e para os quais ainda não existem muitos dados biológicos disponíveis. Entretanto, como foi mostrado, essas abordagens encontram-se em posições quase que opostas em termos de vantagens práticas e aplicabilidade. Realizar um estudo de process tracing causal requer uma quantidade de dados que nem sempre está disponível no meio ambiental, para que toda a cadeia de processos envolvidos no tema estudado possa ser acompanhada. Por outro lado, quando esses dados existem, as possibilidades explicativas são, na mai- oria dos casos, bem superiores às das outras abordagens. Já o uso de contrafatuais requer, pelo menos em tese, uma quantidade menor de dados por ser um exercício de certa forma "fictício"; porém, para que os resultados possam ser transpostos para a realidade, precisa estar solidamente fundada no campo teórico. Por isso, o uso complementar dessas e das outras abordagens, em um ou mais estudos sobre o mesmo tema de política ambiental, é extremamente útil para o desenvolvimento empírico e teórico dessa subdisciplina.

QUADRO 2 - VANTAGENS E LIMITACÕES DE CINCO DAS PRINCIPAIS ABORDAGENS QUALITATIVAS UTILIZADAS NA METODOLOGIA DE ESTUDO DE CASO PARA AS PESQUISAS SOBRE POLÍTICA AMBIENTAL

\begin{tabular}{|c|c|c|}
\hline Tipo de abordagem & Vantagens & Desvantagens \\
\hline Análises de covariância & $\begin{array}{l}\text { Sua semelhança com um experimento } \\
\text { controlado favorece os casos em que as } \\
\text { conseqüências políticas estão fortemente } \\
\text { ligadas a fatores estritamente ambientais; } \\
\text { várias subabordagens podem ser utilizadas; } \\
\text { não é necessário realizar observações } \\
\text { empíricas de todo processo causal, sendo } \\
\text { possível extrair conclusões abstratas } \\
\text { baseadas na teoria que está sendo utilizada }\end{array}$ & $\begin{array}{c}\text { O estudo pode ser afetado } \\
\text { negativamente (ou ser impossivel } \\
\text { de realizar) se houver falta de } \\
\text { teorias robustas }\end{array}$ \\
\hline Uso de contrafatuais & $\begin{array}{l}\text { Permite delinear explicações, criar } \\
\text { hipóteses e até mesmo teorias quando não } \\
\text { há grandes quantidade de informações e/ou } \\
\text { casos observáveis no mundo real }\end{array}$ & $\begin{array}{l}\text { Apesar da existência de teorias de } \\
\text { embasamento não ser sempre } \\
\text { necessária, as análises de } \\
\text { contrafatuais de boa qualidade } \\
\text { preferencialmente devem ter forte } \\
\text { embasamento teórico, o que nem } \\
\text { sempre é possivel }\end{array}$ \\
\hline Process tracing causal & $\begin{array}{l}\text { Fornece explicações robustas e completas } \\
\text { para problemas políticos ambientais; } \\
\text { permite tanto elementos dedutivos (com } \\
\text { uso de teorias disponíveis) quanto indutivos } \\
\text { (com a possibilidade de encontrar variáveis } \\
\text { acidentalmente omitidas) }\end{array}$ & $\begin{array}{l}\text { Necessita de evidências contínuas } \\
\text { entre a causa e efeito do tema } \\
\text { pesquisado, freqüentemente } \\
\text { indisponível para as questões } \\
\text { político-ambientais; pode ser } \\
\text { inviabilizada quando não há } \\
\text { teorias robustas para serem } \\
\text { usadas nas deduções; variáveis } \\
\text { omitidas acidentalmente podem } \\
\text { causar erros inferenciais graves, o } \\
\text { que pode incluir variáveis } \\
\text { socioambientais ainda não } \\
\text { conhecidas }\end{array}$ \\
\hline Testes de congruência & $\begin{array}{l}\text { Aliada à(s) teoria(s) disponível(eis), é } \\
\text { possível criar predições ricas com base nas } \\
\text { mais diversas fontes e sobre diversos } \\
\text { fatores do processo, sendo possível utilizar } \\
\text { índices e outros indicadores } \\
\text { socioambientais }\end{array}$ & $\begin{array}{c}\text { É difícil de aplicar se não houver } \\
\text { teorias robustas que possam ser } \\
\text { usadas como base para as } \\
\text { predições ou dados disponíveis } \\
\text { sobre o tema }\end{array}$ \\
\hline $\begin{array}{l}\text { Comparação entre } \\
\text { casos }\end{array}$ & $\begin{array}{c}\text { Maior capacidade de extrapolação; maior } \\
\text { facilidade de aplicar teorias de outras } \\
\text { áreas; possibilidade de criar teorias } \\
\text { tipológicas. }\end{array}$ & $\begin{array}{l}\text { Possiveis erros inferenciais; } \\
\text { perigo de atribuir muita } \\
\text { representatividade aos casos; } \\
\text { dificuldade de encontrar casos } \\
\text { passíveis de serem comparados }\end{array}$ \\
\hline
\end{tabular}

FONTE: a autora, a partir de Fearon (1991), Bennett (2004) e Blatter e Blume (2007; 2008a; 2008b). 


\section{CONCLUSÕES}

A interface política-meio ambiente é uma área com inúmeras possibilidades de estudo e que, apesar de requerer alguns cuidados metodológicos distintos, pode beneficiar-se consideravelmente de estudos de caso e suas diversas possibilidades de análise e extração de inferências.

Foi visto que as cinco abordagens utilizadas nos estudos de caso discutidas aqui (análises de covariância, uso de contrafatuais, process tracing causal, testes de congruência e comparação entre casos) podem e devem ser utilizadas de maneira complementar. Seria interessante, também, promover mais estudos colaborativos entre diversos pesquisadores e grupos de pesquisa, otimizando o uso das abordagens possíveis e sua complementaridade. Afinal, os estudos em política ambiental vêm contribuindo de maneira crescente para a Ciência Política como um todo, e a metodologia de estudos de caso é mais um instrumento para que isso continue a acontecer.

Andrea Steiner (ecodea@gmail.com) é Doutoranda em Ciência Política pela Universidade Federal de Pernambuco (UFPE).

\section{REFERÊNCIAS BIBLIOGRÁFICAS}

BENNETT, A. 2004. Case Study Methods: Design, Use, and Comparative Advantages. In: SPRINZ, D. F. \& WOLINSKY-NAHMIAS, Y. (eds.). Models, Numbers, and Cases: Methods for Studying International Relations. Ann Arbor: University of Michigan.

BENNETT, A. \& ELMAN, C. 2006. Qualitative Research: Recent Developments in Case Study Methods. Annual Review of Political Science, Palo Alto, v. 9, p. 455-476, June.

BLATTER, J. 2004. From "Spaces of Place" to "Spaces of Flows": Territorial and Functional Governance in Cross-Border Regions in Europe and North America. International Journal of Urban and Regional Research, Oxford (UK), v. 28 , n. 3, p. 530-548, Sept.

BLATTER, J. \& BLUME, T. 2007. Beyond the Co-Variational Template: Alternative Directions in Case Study Methodology. In: GENERAL CONFERENCE OF THE EUROPEAN CONSORTIUM FOR POLITICAL RESEARCH, 4, Pisa (Italy), 6-8.Sept. Essex (UK): University of Essex.

2008a. Co-Variation and Causal Process Tracing Revisited: Clarifying New Directions for Causal Inference and Generalization in Case Study Methodology. Qualitative Methods, Thousand Oaks, v. 6, n. 1, p. 29-34, Spring.

2008b. In Search of Co-variance, Causal Mechanisms or Congruence? Towards a Plu- ral Understanding of Case Studies. Swiss Political Science Review, St. Gallen, v. 14, n. 2, p. 315-356.

CHOUCRI, N. 1993. Introduction: Theoretical, Empirical, and Policy Perspectives. In: Global Accord. Cambridge, Mass.: MIT.

DESCOLA, P. \& PÁLSSON, G. 1996. Nature and Society: Anthropological Perspectives. London: Routledge.

FALLETI, T. G. 2006. Theory-Guided ProcessTracing in Comparative Politics: Something Old, Something New. Newsletter of the Organized Section in Comparative Politics of the American Political Science Association, Notre Dame, v. 17, n. 1, p. 9-14, Winter. Disponível em: http://www.polisci.upenn.edu/ $\sim$ falleti/Falleti-CP-APSANewsletter06TGPT.pdf. Acesso em: 16.dez.2010.

FEARON, J. D. 1991. Counterfactuals and Hypothesis Testing in Political Science. World Politics, Baltimore, v. 43, n. 2, p. 169-195.

FERNANDES, V. \& SAMPAIO, C. A. C. Problemática ambiental ou problemática socioambiental? A natureza da relação sociedade/meio ambiente. Desenvolvimento e Meio Ambiente, Curitiba, n. 18, p. 87-94. Disponível em: http:/ojs.c3sl.ufpr.br/ojs2/index.php/ made/article/download/13427/9051. Acesso em: 16.dez.2010.

FITZGERALD, A. 2006. The Reification of the 
Culture/Nature Dichotomy in Classical Social Theory: Implications for the Study of Animals and Society. In: ANNUAL MEETING OF THE AMERICAN SOCIOLOGICAL ASSOCIATION, 101., Montreal, 11.Aug. Washington (DC): American Sociological Association.

FOSTER, J. B. 2005. A ecologia de Marx: materialismo e natureza. Rio de Janeiro: Civilização Brasileira.

GERRING, J. 2004. What Is a Case Study and What Is It Good for? American Political Science Review, Los Angeles, v. 98, n. 2, p. 341-354, May. Disponível em: http:// web.rollins.edu/ ddavison/Spring08/ Gerring_CaseStudies.pdf. Acesso em: 16.dez. 2010

HAAS, P. 1989. Do Regimes Matter? Epistemic Communities and Mediterranean Pollution Control. International Organization, Cambridge, Mass.., v. 43, n. 3, p. 377-403, Summer.

HELM, C. \& SPRINZ, D. 2000. Measuring the Effectiveness of International Environmental Regimes. Journal of Conflict Resolution, Thousand Oaks, v. 44, n. 5, p. 630-652, Oct. Disponível em: http://www.uni-potsdam.de/u/ sprinz/doc/Sprinz_Helm2000.pdf. Acesso em: 16.dez. 2010

HOMER-DIXON, T. F. 1993. Physical Dimensions of Global Change. In: CHOUCRI, N. (ed.). Global Accord. Cambridge, Mass.: MIT.

1996. Strategies for Studying Causation in Complex Ecological-Political Systems. The Journal of Environment Development, Thousand Oaks, v. 5, n. 2, p. 132-148, June. Disponível em: http://www.library.utoronto.ca/ pcs/eps/method/methods1.htm. Acesso em: 16.dez. 2010

KEOHANE, R. O.; HAAS, P. M. \& LEVY, P. M. 1993. The Effectiveness of International Environmental Institutions. In: HAAS, P. M.; KEOHANE, R. O. \& LEVY, M. A. Institutions for the Earth. Cambridge, Mass.: MIT.

KING, G.; KEOHANE, R. O. \& VERBA, S. 1994. Designing Social Inquiry: Scientific Inference in Qualitative Research. Princeton: Princeton University.

KOTOV, V. \& NIKITINA, E. 1998. The Implementation and Effectiveness of the Acid Rain Regime in Russia. In: VICTOR, D. G.; RAUSTIALA, K. \& SKOLNIKOFF, E. B. The Implementation and Effectiveness of International Environmental Commitments: Theory and Practice. Laxenburg (Austria): International Institute for Applied Systems Analyses.

LE PRESTRE, P. G. 2002. The CBD at Ten: The Long Road to Effectiveness. Journal of International Wildlife Law \& Policy, London, v. 5 , n. 3, p. 269-285, Summer. Disponível em: http://www.geog.umontreal.ca/donnees/ geo6815GEO6815_Lecture\%20cours\%2014_ LePrestre.pdf. Acesso em: 16.dez.2010.

2003. Governing Global Biodiversity: The Evolution and Implementation of the Convention on Biological Diversity. Chippenham: Ashgate.

MAZOTTI, T. B. 1997. Representação social de "problema ambiental": uma contribuição à educação ambiental. Revista Brasileira de Estudos Pedagógicos, Brasília, v. 78, n. 188-189190, p. 86-123. Disponível em: http:// www.rbep.inep.gov.br/index.php/RBEP/ article/viewFile/257/258. Acesso em: 16.dez.2010.

MILES, E. L.; UNDERDAL, A.; ANDRESEN, S.; WETTESTAD, J.; SKJ/ERSETH, J. B. \& CARLIN, E. M. 2002. Environmental Regime Effectiveness: Confronting Theory with Evidence. Cambridge, Mass.: MIT.

MITCHELL, R. 1994. Intentional Oil Pollution at Sea: Environmental Policy and Treaty Compliance. Cambridge, Mass.: MIT.

.2006. Problem Structure, Institutional Design, and the Relative Effectiveness of International Environmental Agreements. Global Environmental Politics, Cambridge, Mass.:, v. 6, n. 3, p. 72-89, Aug.

MITCHELL, R. \& BERNAUER, T. 1998. Empirical Research on International Environmental Policy: Designing Qualitative Case Studies. Journal of Environment \& Development, Thousand Oaks, v. 7, n. 1, p. 4-31, Mar. 
2004. Beyond Story-telling: Designing Case Study Research in International Environmental Policy. In: SPRINZ, D. F. \& WOLINSKYNAHMIAS, Y. Models, Numbers, and Cases: Methods for Studying International Relations. Ann Arbor: University of Michigan.

ROSENDAL, G. K. 2000. The Convention on Biological Diversity and Developing Countries. Dordrecht: Kluwer.

SPRINZ, D. F. 2005. Regime Effectiveness: The Next Wave of Research. In: BERLIN CONFERENCE ON THE HUMAN DIMENSIONS OF GLOBAL ENVIRONMENTAL CHANGE, Potsdam, 2-3.Dec. Potsdam: Potsdam Institute for Climate Impact Research. Disponível em: http://www.unipotsdam.de/u/sprinz/doc/Sprinz. Effectiveness.Next_Wave.pdf. Acesso em: 16.dez.010.

SPRINZ, D. F. \& HELM, C. 1999. The Effect of Global Environmental Regimes: A Measurement Concept. International Political Science Review, Thousand Oaks, v. 20, p. 359-369, Sept.

SUNDGREN, J. 1993. Lateral Pressure Theory as Applied to Global Warming: An Initial Assessment. International Political Science Review, Thousand Oaks, v. 14, n. 1, p. 87101, Jan.

TANSEY, O. 2007. Process Tracing and Elite Interviewing: A Case for Non-probability Sampling. Political Science \& Politics, Washington (DC), v. 40, n. 4, p. 765-772, Oct. Disponível em: http://www.nuffield.ox.ac.uk/ politics/papers/2006/tansey.pdf. Acesso em: 16.dez.2010.

UNDERDAL, A. 1992. The Concept of Regime Effectiveness. Cooperation and Conflict, Thousand Oaks, v. 27, n. 3, p. 227-240, Sept.

2002. One Question, Two Answers. In: MILES, E. L.; UNDERDAL, A.; ANDRESEN,
S.; WETTESTAD, J.; SKJÆRSETH, J. B. \& CARLIN, E. M. 2002. Environmental Regime Effectiveness: Confronting Theory with Evidence. Cambridge, Mass.: MIT.

VAN WYNSBERGHE, R. \& KHAN, S. 2007. Redefining Case Study. International Journal of Qualitative Methods, Edmonton, v. 6, n. 2, p. 80-94. Disponível em: http:// ejournals.library.ualberta.ca/index.php/IJQM/ article/view/542/2495. Acesso em: 16.dez.2010.

VICTOR, D. G.; RAUSTIALA, K. \& SKOLNIKOFF, E. B. 1998. The Implementation and Effectiveness of International Environmental Commitments: Theory and Practice. Laxenburg (Austria): International Institute for Applied Systems Analyses.

WETTESTAD, J. 2002. The Vienna Convention and Montreal Protocol on Ozone-Layer Depletion. In: MILES, E. L.; UNDERDAL, A.; ANDRESEN, S.; WETTESTAD, J.; SKJÆRSETH, J. B. \& CARLIN, E. M. Environmental Regime Effectiveness: Confronting Theory with Evidence. Cambridge, Mass.: MIT.

WHITE JR., L. 2000. The Historical Roots of Our Ecological Crisis. In: GOLDFARB, T. D. (ed). Notable Selections in Environmental Studies. Guilford: Dushkin.

YIN, R. K. 2009. Case Study Research: Design and Methods. Thousand Oaks: Sage.

YOUNG, O. R. 1994. The Problem of Scale in Human/Environment Relationships. Journal of Theoretical Politics, Thousand Oaks, v. 6, n. 4, p. 429-447, Oct.

ZÜRN, M. 1998. The Rise of International Environmental Politics: A Review of Current Research. World Politics, Baltimore, v. 50, n. 4, p. 617-649, July. 

LIMITATIONS

\section{Andréa Steiner}

The analysis of environmental issues in a political context is a topic that attracts growing attention within Political Science, yet requires specific methodological considerations. One of methods that is most frequently employed in research linked to environmental policy is that of case studies. The purpose of this article is to discuss the role of such a methodology within the sub-discipline. Some general conceptual issues on the method and the advantages and disadvantages it offers are sketched out. Furthermore, the study of environmental politics is distinguished from other research topics within Political Science, contextualizing its specific methodological needs and the role of case studies in research on environmental politics is analyzed, looking at its inherent ambiguities, the advantages and general limitations of the methodology and five forms of analysis and inference: covariance analysis, counterfactual analysis, causal process tracing and tests for congruence and comparison of cases. Of these five approaches, two stand out as particularly relevant for political and environmental research, although they occupy almost opposite positions in terms of practical advantages and applicability: causal process tracing and counterfactual analysis. The complementary use of these and other approaches, whether in one or more studies on issues of environmental policy, is extremely useful for the empirical and theoretical development of the sub-discipline.

KEYWORDS: Case Studies; Environmental Policy; Methodologies in Political Science; Qualitative Methodologies. 
L'UTILISATION D'ETUDES DE CAS DANS DES RECHERCHES SUR LA POLITIQUE DE L'ENVIRONNEMENT: LES AVANTAGES ET LES LIMITATIONS

\section{Andréa Steiner}

L'analyse des questions de l'environnement dans un contexte politique est un domaine d'étude en plein essor dans la Science Politique, mais qui demande des considérations méthodologiques spécifiques. L'une des méthodes les plus fréquemment utilisées dans les recherches liées à la politique de l'environnement, est l'étude de cas. L'objectif de cet article est de discuter le rôle de cette méthodologie dans cette sous-discipline. Les questions conceptuelles générales sur la méthode sont délimitées, avec ses avantages et inconvénients; l'étude de la politique de l'environnement se distingue des autres thèmes de recherche dans la Science Politique, en incluant ses nécessités méthodologiques spécifiques; et on analyse le rôle des études de cas dans les recherches sur la politique de l'environnement, en abordant ses ambigüités inhérentes et les avantages et limitations générales de la méthodologie et de cinq formes d'analyse et extraction de conséquences: analyse de la moyenne, utilisation de contrefactuelles, processus causal de traçage et test de congruence et comparaison entre cas. Parmi ces cinq approches, deux sont en évidence pour les recherches politiques et d'environnement, malgré le fait qu'elles occupent des positions pratiquement opposées par rapport aux avantages pratiques et l'applicabilité: processus causal de traçage et utilisation de contrefactuelles. L'utilisation complémentaire de ces approches et d'autres, soit dans une étude ou plus, sur des thèmes de politique d'environnement, est extrêmement utile pour le développement empirique et théorique de cette sous-discipline.

MOTS-CLES: études de cas; politique d'environnement; méthodologie en Science Politique; méthodologie qualitative. 